\title{
On-line, non-Newtonian capillary rheometry for continuous and in-line coatings production
}

\author{
Luo, Shicong; Erik Weinell, Claus; Okkels, Fridolin; Landeira Østergård, Anders ; Kiil, Søren
}

Published in:

Journal of Coatings Technology and Research

Link to article, DOI:

$10.1007 / \mathrm{s} 11998-020-00447-9$

Publication date:

2021

Document Version

Peer reviewed version

Link back to DTU Orbit

Citation (APA):

Luo, S., Erik Weinell, C., Okkels, F., Landeira Østergård, A., \& Kiil, S. (2021). On-line, non-Newtonian capillary rheometry for continuous and in-line coatings production. Journal of Coatings Technology and Research, 18, 611-626. https://doi.org/10.1007/s11998-020-00447-9

\section{General rights}

Copyright and moral rights for the publications made accessible in the public portal are retained by the authors and/or other copyright owners and it is a condition of accessing publications that users recognise and abide by the legal requirements associated with these rights.

- Users may download and print one copy of any publication from the public portal for the purpose of private study or research.

- You may not further distribute the material or use it for any profit-making activity or commercial gain

- You may freely distribute the URL identifying the publication in the public portal 


\title{
On-line, non-Newtonian capillary rheometry for continuous and in-line coatings production
}

Shicong Luo, ${ }^{\mathrm{a}}$ Claus Erik Weinell, ${ }^{\mathrm{a}}$ Fridolin Okkels, ${ }^{\mathrm{b}}$ Anders Landeira $\emptyset$ stergård, ${ }^{\mathrm{b}}$ Søren Kiil ${ }^{\mathrm{T}}$

${ }^{a}$ Department of Chemical and Biochemical Engineering, Technical University of Denmark, DTU, Building 229, 2800 Kgs. Lyngby, Denmark

${ }^{b}$ Fluidan Aps, Diplomvej 381, 2800 Kgs. Lyngby, Denmark

${ }^{\top}$ Corresponding author, Department of Chemical and Biochemical Engineering, Technical University of Denmark, DTU, Building 229, 2800 Kgs. Lyngby, Denmark. e-mail: sk@kt.dtu.dk

\begin{abstract}
Moving from traditional batch production into in-line or continuous coatings production requires accurate on-line quality control instruments. The aim of the present work was to investigate the principle of non-Newtonian capillary rheometry for quality control purposes. In the investigation, three series of acrylic-based viscoelastic coating samples with different types and concentrations of pigments and thickening agents were used, and the rheological measurements were compared to results obtained with the so-called Stormer viscometer and an advanced off-line rheometer. A detailed analysis of the potential measurement implications was also conducted.

For shear stresses from 15.0 to $350.0 \mathrm{~Pa}$ (the upper boundary), the novel capillary rheometer was found to provide results in good quantitative agreement with the advanced rheometer when sample holding time, and thereby shear history, was properly controlled. At a shear stress between $1.0 \mathrm{~Pa}$ (lower boundary) and 15.0 Pa, the agreement was less good, with a difference in results of the nonNewtonian capillary rheometer and the advanced rheometer between 15 and $74 \%$.

The resolution of the capillary rheometer was sufficiently high to allow detection of the rheology changes associated with variations in coating formulations of pigment volume and rheology modifier concentrations.

In summary, for fast on-line evaluation of coating rheology, the principle of capillarity has been demonstrated to be a varied and robust technique.
\end{abstract}

Keywords: on-line measurement, quality control, viscosity, capillary rheometer 


\section{Nomenclature}

\begin{tabular}{|c|c|}
\hline $\mathrm{D}$ & Diameter of the capillary tube (m) \\
\hline $\mathrm{f}_{\mathrm{s}}$ & Moody friction factor of the fluid in a straight pipe \\
\hline $\mathrm{k}_{\mathrm{b}}$ & Bend loss coefficient \\
\hline $\mathrm{L}$ & Length of the capillary tube (m) \\
\hline Q & Flow rate of the sample $\left(\mathrm{m}^{3} / \mathrm{s}\right)$ \\
\hline $\mathrm{R}$ & Radius of the capillary tube (m) \\
\hline $\mathrm{R}_{\mathrm{b}}$ & Radius of the bend (m) \\
\hline $\mathrm{u}$ & Velocity of the fluid (m/s) \\
\hline$\Delta \mathrm{P}$ & Total pressure drop caused by the friction in the capillary tube $(\mathrm{Pa})$ \\
\hline$\Delta \mathrm{P}_{\mathrm{f}, \mathrm{y}}$ & Pressure drop to overcome the yield stress $(\mathrm{Pa})$ \\
\hline$\Delta \mathrm{P}_{\text {bend }}$ & Total pressure drop inside a bend $(\mathrm{Pa})$ \\
\hline$\Delta \mathrm{P}_{\mathrm{f}, \text { bend }}$ & Pressure drop caused by the friction inside a bend $(\mathrm{Pa})$ \\
\hline$\Delta \mathrm{P}_{\text {add }}$ & $\begin{array}{l}\text { Additional pressure drop generated by the change of direction of the fluid inside } \\
\text { a bend }(\mathrm{Pa})\end{array}$ \\
\hline \multicolumn{2}{|l|}{ Greek } \\
\hline$\alpha$ & $\begin{array}{l}\text { Calculated ratio between the viscosity results measured by the non-Newtonian } \\
\text { capillary or the advanced rheometer and the Stormer viscometer }\end{array}$ \\
\hline$\beta$ & $\begin{array}{l}\text { Calculated ratio value between the results of the non-Newtonian capillary } \\
\text { rheometer with and without a holding time and the advanced rheometer }\end{array}$ \\
\hline$\eta$ & Viscosity of the fluid $(\mathrm{Pa} \cdot \mathrm{s})$ \\
\hline$\theta$ & $\theta$ is the angle of the bend $\left(^{\circ}\right)$ \\
\hline$\dot{\gamma_{\mathrm{a}}}$ & Apparent shear rate applied to the measured sample $\left(\mathrm{s}^{-1}\right)$ \\
\hline$\dot{\gamma_{\mathrm{w}}}$ & Shear rate at the tube wall $\left(\mathrm{s}^{-1}\right)$ \\
\hline$\lambda$ & Reduced PVC value (PVC/CPVC) \\
\hline$\rho$ & Density of the fluid $\left(\mathrm{kg} / \mathrm{m}^{3}\right)$ \\
\hline$\tau_{\mathrm{w}}$ & Shear stress at the tube wall $(\mathrm{Pa})$ \\
\hline
\end{tabular}

\section{Introduction}

The coatings industry of today is challenged with fierce competition, demanding customer requirements, such as sustainable and efficient products, and high costs of raw materials. In 
addition, in many countries legislation restricts the type, and thereby number, of raw materials that can be used when formulating coatings. To meet some of these challenges and enable a more flexible approach to production, investigations on how to move current or future batch productions to in-line semi-continuous or truly continuous manufacturing processes, are ongoing. Similar trends have affected other industries in the past 20 years, pharmaceutical processing plants perhaps being the most important example [1-3].

Some of the expected advantages of continuous or semi-continuous coating production are faster and cheaper quality control, lower operation and labor costs, and a reduced risk of human errors. In-line procedures may also reduce production time, leading to a higher efficiency of manufacturing $[4,5]$. However, at present, obstacles are also evident. One of them is the lack of adequate manufacturing equipment, the other is the limited options for on-line quality control instruments [6].

In present batch productions of coatings, the typical quality control methods in use include the Hegman gauge (for evaluation of the degree of pigment dispersion), a viscometer (for a singleshear rate viscosity measurement), and the spectrophotometer (for colour evaluation) [7, 8]. These methods, while simple and reliable for repeated use, require human interaction in a non-automized manner and therefore are not suitable for true in-line coatings production; new principles and novel types of equipment are needed [9].

Furthermore, traditional quality control methods take a relatively long time to conduct. The evaluation of viscosity, for example, requires manual sampling and may, mainly because of thermostating prior to the measurement, take from 20 to 60 minutes, depending on the adopted company procedures [10]. Similarly, the current colour evaluation techniques require one to two days of coating drying prior to the actual dry film measurement. Faster colour measurements are possible, but they do require calibration against dry samples, with a dependency on formulation variables and production conditions [11]. In addition, when products do not meet the requirements, time must be allowed for making formulation adjustments.

In the present work, we explore an on-line, multi-shear stress, rheological technique based on the principle of capillary flow. The measurement range, repeatability, advantages and disadvantages of the method are investigated, and, for validation, the method is compared to results obtained with selected viscosity analysis instruments currently in use in the coatings industry. 


\section{Previous work on on-line and in-line rheometry}

Coating rheology is affected by temperature, the current shear stress, and the shear history of the coating under investigation [12]. However, in current coating productions, these variables are not always accurately controlled, which can lead to fluctuations in the coatings quality [13].

A range of on-line rheology technologies, such as the ultrasound-based rheometer, the capillary rheometer, and the oscillating piston rheometer are presented in Table 1. The latter utilises an oscillating piston and two alternating electromagnetic coils in the measuring cell. These coils move the piston forwards and backwards, and during a measurement, a small amount of liquid is drawn into the chamber. During the movement of the piston, the sample viscosity is determined by measuring the piston's so-called cycling time (i.e. stroke frequency) while a certain force is applied. When the viscosity of the liquid goes up, the cycling time increases $[14,15]$. However, due to the narrow gap between the piston and the sensor wall, where the actual measurement takes place, the equipment cannot handle liquids with particle diameters larger than $25 \mu \mathrm{m}$ [15] and is therefore of limited use in the coatings industry, where pigment agglomerates or filler particles can be substantially larger. 
Table 1. Comparison of viscometers (simple) and rheometers (advanced) for in-line and on-line measurements.

\begin{tabular}{|c|c|c|c|c|c|c|}
\hline Method & Principle & Advantages & Disadvantages & Viscosity range & Shear rate range & References \\
\hline $\begin{array}{l}\text { Off-line } \\
\text { rotational } \\
\text { viscometer }\end{array}$ & $\begin{array}{l}\text { A paddle, cylinder, or disc is rotated } \\
\text { in a liquid. }\end{array}$ & $\begin{array}{l}\text { Simple and fast. Low cost. Easy to } \\
\text { use. }\end{array}$ & $\begin{array}{l}\text { Relative long time is required for } \\
\text { temperature control of the sample }\end{array}$ & $\begin{array}{l}0.15-4.0 \mathrm{~Pa} \cdot \mathrm{s} \\
{[17]}\end{array}$ & $0-50 \mathrm{~s}^{-1}[22]$ & $\begin{array}{l}\text { 2006,[16]; } \\
2014,[27]\end{array}$ \\
\hline $\begin{array}{l}\text { Falling sphere / } \\
\text { raising bubble } \\
\text { method }\end{array}$ & $\begin{array}{l}\text { Metal or plastic spheres of different } \\
\text { diameter and materials fall under } \\
\text { gravity or an air bubble rises in the } \\
\text { sample material }\end{array}$ & Easy to use. Inexpensive. & $\begin{array}{l}\text { Not suitable for non-Newtonian and } \\
\text { opaque materials. }\end{array}$ & $\begin{array}{l}5 \cdot 10^{-4}-100 \mathrm{~Pa} \cdot \mathrm{s} \\
{[18]}\end{array}$ & $0.1-100 \mathrm{~s}^{-1}[23]$ & $\begin{array}{l}2010,[28] \\
1964,[29]\end{array}$ \\
\hline $\begin{array}{l}\text { Ultrasound } \\
\text { rheometer }\end{array}$ & $\begin{array}{l}\text { From the surface of the tube or } \\
\text { container, sound waves are emitted } \\
\text { to the sample. The reflection time } \\
\text { and the strength of the reflected } \\
\text { signal are measured. }\end{array}$ & $\begin{array}{l}\text { Real-time and in-line measurement. } \\
\text { Sensitive to viscoelastic properties of } \\
\text { sample material. }\end{array}$ & $\begin{array}{l}\text { Air bubbles can interfere. Requires a } \\
\text { high surface finish of the pipe and } \\
\text { container. }\end{array}$ & $\begin{array}{l}0.01-1000 \mathrm{~Pa} \cdot \mathrm{s} \\
{[19]}\end{array}$ & $10-1000 \mathrm{~s}^{-1}[24]$ & $\begin{array}{l}2004,[30] ; \\
2017,[31] ; \\
2008,[32] \\
2020,[33]\end{array}$ \\
\hline $\begin{array}{l}\text { Oscillating } \\
\text { piston/ } \\
\text { electromagnetic } \\
\text { viscometer }\end{array}$ & $\begin{array}{l}\text { An oscillating piston and two } \\
\text { alternating electromagnetic coils, } \\
\text { allow a measurement of the piston's } \\
\text { round moving time. }\end{array}$ & $\begin{array}{l}\text { Easy to clean, in-line measurement (if } \\
\text { not obstructing equipment operation), } \\
\text { able to handle high pressure and high } \\
\text { temperature conditions. }\end{array}$ & $\begin{array}{l}\text { Sensitive to contamination. Only } \\
\text { pigment-free samples or samples } \\
\text { with particle sizes smaller than } 25 \\
\mu \mathrm{m} \text {. }\end{array}$ & $\begin{array}{l}2 \cdot 10^{-5}-100 \mathrm{~Pa} \cdot \mathrm{s} \\
{[20]}\end{array}$ & $\begin{array}{l}5 \cdot 10^{-2}-200 \mathrm{~s}^{-1} \\
{[25]}\end{array}$ & $\begin{array}{l}2014,[14] \\
2003,[15]\end{array}$ \\
\hline $\begin{array}{l}\text { Capillary } \\
\text { rheometer }\end{array}$ & $\begin{array}{l}\text { The sample viscosity is estimated } \\
\text { based on the flow rate and the } \\
\text { pressure drop in a capillary tube. }\end{array}$ & $\begin{array}{l}\text { Simple and fast measurement. Can } \\
\text { handle samples with high pigment } \\
\text { concentrations. }\end{array}$ & Not accurate at low shear rates. & $1-1000 \mathrm{~Pa} \cdot \mathrm{s}[15]$ & $1-1000 \mathrm{~s}^{-1}[26]$ & $\begin{array}{l}2011,[34] ; \\
1994,[35] ; \\
2017,[36] ;\end{array}$ \\
\hline $\begin{array}{l}\text { Advanced } \\
\text { rheometer }\end{array}$ & $\begin{array}{l}\text { Off-line rotational rheometer with a } \\
\text { wide range of accessories, such as } \\
\text { cone and plate, parallel plates, and } \\
\text { concentric cylinder. }\end{array}$ & $\begin{array}{l}\text { High accuracy and flexible } \\
\text { measurement. Small sample sizes. } \\
\text { High repeatability. Easy to clean. }\end{array}$ & $\begin{array}{l}\text { Expensive. Generally not suitable } \\
\text { for industrial production. Relatively } \\
\text { long time for sample handling and } \\
\text { temperature control. }\end{array}$ & $\begin{array}{l}5 \cdot 10^{-3}-10^{4} \mathrm{~Pa} \cdot \mathrm{s} \\
{[21]}\end{array}$ & $10^{-4}-10^{4} \mathrm{~s}^{-1}[21]$ & $2014,[27]$ \\
\hline
\end{tabular}


The ultrasound rheometer is based on a sampling of the sound wave intensity attenuation [30]. This method was first introduced by Mason et al. in 1949 [37], and Hertz et al. [38] performed sound wave measurements on food products. Later developments have shown that the ultrasoundbased methods are capable of measuring the flow rate, the viscosity, the density, the dielectric constant (relative permittivity), and the conductivity of fluids [39]. When applied to a coatings production process, the method proved to be a direct way of measuring the flow rates of liquid streams [40] and a combination of the ultrasound velocity profiling and pressure difference can be used to estimate the viscosity of both Newtonian and non-Newtonian fluids [41]. However, the method was influenced by air bubbles, originating from the dispersion, and the shape of pigment particles [42].

The capillary viscometer is another device for measuring the rheology of Newtonian fluids [34]. Kalotay [35] used a so-called Coriolis mass flowmeter as a capillary rheometer to measure the viscosity of different fluids, which, according to the authors provided "a reliable and low-cost online viscosity measurement compared with other approaches". The method can estimate the viscosity of the sample by measuring the flow rate and the pressure drop through the capillary tube. It was later (2011) demonstrated that the capillary rheometer could also be used for nonNewtonian fluids at varying shear rates [43]. The so-called scanning capillary tube viscometer has been widely applied to measure the viscosity of blood [44]; however, the main drawback for use on non-Newtonian fluids is that the equipment can measure at one shear rate at a time only [45].

\section{Strategy of the investigation}

The purpose of the present work is to explore a new and fast on-line principle for continuous evaluation of the rheological properties of a coating during production.

Coatings are non-Newtonian fluids, and the viscosity of a coating normally decreases when the applied shear stress (and associated shear rate) increases (i.e. the coating is shear-thinning). Therefore, it is important to evaluate the rheological properties of a coating under different shear stress conditions, such as those of brushing and spraying, but, industrially, due to time constraints, the viscosity is often estimated at one shear stress value only.

Historically, textbooks and articles (see e.g. [78,79,80]) have used the shear rate as the independent variable and viscosity as the dependent variable. However, as pointed out by Eley [81], with the present availability of commercial controlled-stress instrumentation, the shear stress should indeed 
be taken as the independent variable for rheological evaluation of coatings performance. This point of view was adopted here. In the investigation, 14 different coating samples, with a broad variation in the pigment volume concentration (PVC) and the concentration of rheology modifier, are included. For validation of the method, measurements are compared to data obtained with an advanced research rheometer. Points investigated are: the valid measuring ranges of the capillary rheometer, a mapping of parameters affecting the measurements, and a comparison of the nonNewtonian capillary rheometer, the advanced rheometer, and the Stormer viscometer.

\section{Experimental}

\section{Raw materials}

For the analysis, acrylic-based coatings with different types and amounts of pigments were applied. The basic coating formulation consists of an acrylic based resin (Synocryl 874 X40 from Arkema), xylene solvent, a rheology modifier (Crayvallac® Super from Arkema), and either titanium dioxide pigment (Tiona 595 from Cristal Global) or phthalocyanine green pigment (Heliogen Green from BASF).

\section{Coating systems investigated}

To map the effects of PVC and the concentration of rheology modifier on the rheology of the coating system, three series of coatings were prepared as shown in Table 2. All coatings were formulated using a DISPERMAT ${ }^{\circledR}$ LC “dissolver” (disperser) from VMA-GETZMANN GMBH, Germany. 
Table 2. Compositional details, the critical pigment volume concentration (CPVC), and the reduced PVC $(\lambda)$ of the coatings used in the investigation. The critical pigment volume concentration (CPVC) values were estimated using the spatula rub-out oil absorption (OA) method [82]. $\mathrm{RM}=\mathrm{Rheology}$ modifier, $\mathrm{AC}=$ acrylic based coatings, $\mathrm{IP}=$ inorganic pigment content, $\mathrm{OP}=$ organic pigment content.

\begin{tabular}{|c|c|c|c|c|c|c|}
\hline $\begin{array}{c}\text { Experimental } \\
\text { series }\end{array}$ & $\begin{array}{c}\text { Coating } \\
\text { name }\end{array}$ & Pigment type & PVC & CPVC & $\begin{array}{c}\lambda \\
(\mathrm{PVC} / \mathrm{CPVC})\end{array}$ & $\begin{array}{c}\text { RM } \\
(\mathrm{wt} \%)\end{array}$ \\
\hline \multirow{6}{*}{$\begin{array}{c}\text { Variation in } \\
\text { inorganic } \\
\text { pigment } \\
\text { content }\end{array}$} & AC-IP1 & Titanium dioxide & 3.00 & 58.32 & 0.05 & 0.49 \\
\hline & AC-IP2 & Titanium dioxide & 12.72 & 58.32 & 0.22 & 0.49 \\
\hline & AC-IP3 & Titanium dioxide & 18.81 & 58.32 & 0.32 & 0.49 \\
\hline & AC-IP4 & Titanium dioxide & 19.61 & 58.32 & 0.34 & 0.49 \\
\hline & AC-IP5 & Titanium dioxide & 20.39 & 58.32 & 0.35 & 0.49 \\
\hline & AC-IP6 & Titanium dioxide & 35.00 & 58.32 & 0.60 & 0.49 \\
\hline \multirow{4}{*}{$\begin{array}{l}\text { Variation in } \\
\text { the amount of } \\
\text { RM }\end{array}$} & AC-RM1 & Titanium dioxide & 19.61 & 58.32 & 0.34 & 0.23 \\
\hline & AC-RM2 & Titanium dioxide & 19.61 & 58.32 & 0.34 & 0.66 \\
\hline & AC-RM3 & Titanium dioxide & 19.61 & 58.32 & 0.34 & 1.32 \\
\hline & AC-RM4 & Titanium dioxide & 19.61 & 58.32 & 0.34 & 1.98 \\
\hline \multirow{4}{*}{$\begin{array}{c}\text { Variation in } \\
\text { organic } \\
\text { pigment } \\
\text { content }\end{array}$} & AC-OP1 & $\begin{array}{c}\text { Phthalocyanine } \\
\text { green }\end{array}$ & 1.00 & 72.95 & 0.014 & 1.33 \\
\hline & AC-OP2 & $\begin{array}{c}\text { Phthalocyanine } \\
\text { green }\end{array}$ & 5.00 & 72.95 & 0.07 & 1.33 \\
\hline & AC-OP3 & $\begin{array}{c}\text { Phthalocyanine } \\
\text { green }\end{array}$ & 10.00 & 72.95 & 0.14 & 1.33 \\
\hline & AC-OP4 & $\begin{array}{c}\text { Phthalocyanine } \\
\text { green }\end{array}$ & 20.00 & 72.95 & 0.27 & 1.33 \\
\hline
\end{tabular}

\section{Non-Newtonian capillary rheometer}

The rheology of the coating samples, in this work equivalent to the coating viscosity as a function of the shear stress, was measured using a novel so-called non-Newtonian capillary rheometer. This apparatus, which was developed based on the principle of capillary rheometry for laminar flow, is shown schematically in Figure 1. 


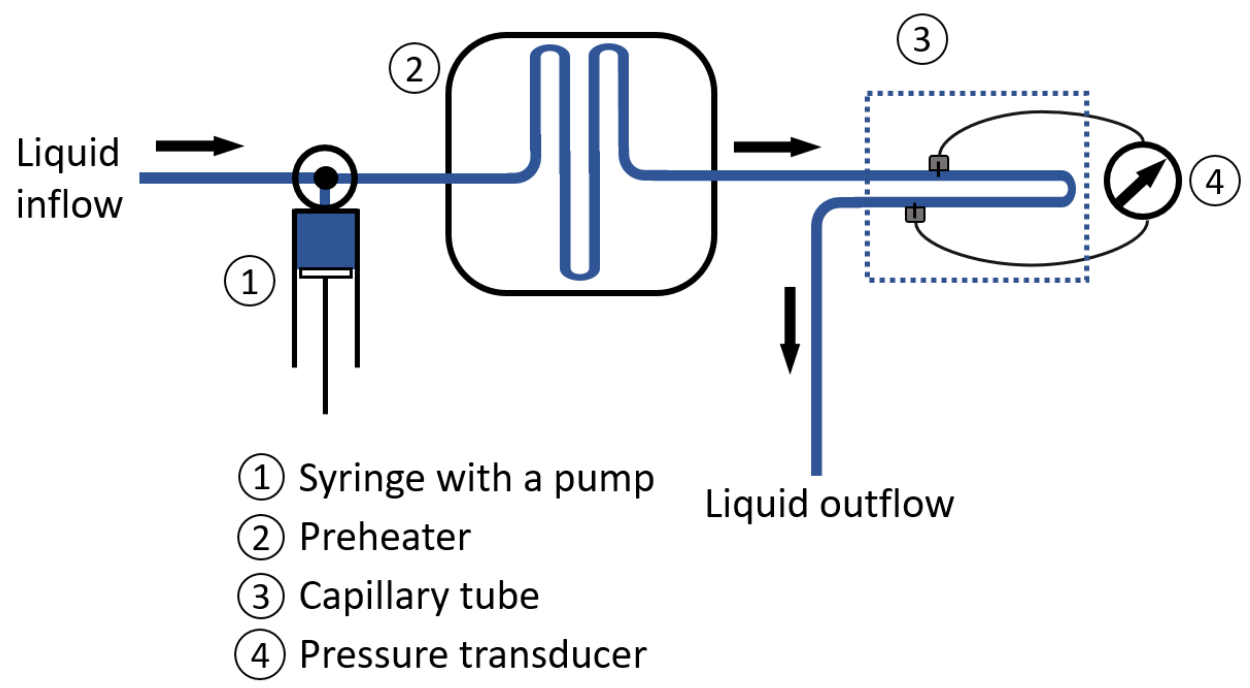

Figure 1. Working principle of the non-Newtonian capillary rheometer.

The cylindrical capillary tube has an inner diameter of $2 \mathrm{~mm}$ and is temperature-controlled (15 to $60{ }^{\circ} \mathrm{C}$ ) using a preheater. The latter is a heat exchanger, where the sample passes through a long channel (folded like a serpentine style tube with several $180^{\circ}$ turns, as indicated in Fig. 1) in order for the sample temperature to equilibrate to the temperature of the surrounding metal parts. The temperature of the metal parts is in turn controlled by a combination of two effects; an airconditioning that keeps the cabinet-air inside the instrument a few degrees colder than the required sample set-point, and small heating elements on the metal parts, which raises the temperature of the local metal parts from the colder air temperature to the final set-point. As indicated in Fig. 1, the pressure drop across the capillary tube is measured by a single differential pressure sensor, connected to the capillary channel at both ends.

Prior to a measurement, a coating sample was re-dispersed at $2000 \mathrm{rpm}$ for three minutes using a high-speed disperser, after which a filling process, using a syringe with a pump, was conducted to displace any cleaning-liquid inside the measuring tube. Subsequently, five $\mathrm{ml}$ of the sample was drawn into the instrument using the syringe and put on hold before being pumped into the capillary tube with a given number of increasing or decreasing pulses (in this case eight pulses). For each pulse, a small amount of fluid is pumped out in 10-30 s, and there is a $3 \mathrm{~s}$ pause between two pulses. A certain flow rate (and thereby shear stress) was established by varying the flow rate of fluid being pumped through in each pulse. The associated pressure drop over the capillary tube 
was measured and used to calculate the viscosity of the sample, and the measurement temperature was controlled to $25 \pm 0.2^{\circ} \mathrm{C}$.

Due to the fairly high viscosities of the coatings, an excessive pressure drop generated inside the flow system, which occasionally led to blocking of the capillary tube when using high flow rates. Consequently, there was an upper critical flow rate above which experiments could not be conducted. An adequate flow rate range was found to be from 100 to $15000 \mu \mathrm{L} / \mathrm{min}$. The relative uncertainty of results generated with the equipment was in all cases lower than $5 \%$.

The coating viscosity is calculated from the pressure drop measured, and known values for the capillary radius and length, as well as the liquid flow rate. For a Newtonian fluid and laminar flow (parabolic velocity distribution within the tube), the viscosity, $\eta$, can be calculated from the Hagenpoiseuilles equation [46]

$$
Q=\frac{\pi R^{4}}{8 L \eta} \Delta P
$$

where $\mathrm{Q}$ is the flow rate of the coating sample and $\Delta \mathrm{P}$ is the pressure drop associated with passing of the liquid through the capillary tube. $\mathrm{R}$ is the radius and $\mathrm{L}$ is the length of the capillary tube. However, according to earlier literature [47, 48, 49], equation (1) cannot be directly applied for non-Newtonian fluids; the shear stress-dependent viscosity of these materials can lead to nonparabolic flow in the capillary tube. In this case, the Weissenberg-Rabinowitsch equation, underlying assumptions of a no slip condition at the tube wall and truly laminar fluid flow (i.e., pipe flow Renoylds numbers below about 1500 [50]), must be used to estimate the fluid viscosity at the capillary tube wall $[47,48,49]$. An apparent shear rate, $\gamma_{\mathrm{a}}$, and the capillary wall shear stress, $\tau_{\mathrm{w}}$, are thereby calculated from

$$
\begin{aligned}
\dot{\gamma}_{a} & =\frac{4 Q}{\pi R^{3}} \\
\tau_{w} & =\frac{R \Delta P}{2 L}
\end{aligned}
$$

The shear rate at the tube wall, $\dot{\gamma}_{\mathrm{w}}$, is estimated from

$$
\dot{\gamma_{w}}=\dot{\gamma_{a}}\left(0.25\left(3+\frac{d \ln \left(\dot{\gamma_{a}}\right)}{d \ln \left(\tau_{w}\right)}\right)\right)
$$

Finally, the viscosity of a non-Newtonian fluid in the capillary tube is calculated from

$$
\eta=\frac{\tau_{w}}{\dot{\gamma_{w}}}
$$




\section{The advanced rheometer}

For validation of the results of the non-Newtonian capillary rheometer, an advanced Discovery Hybrid Rheometer from TA Instruments was used. In this case, all samples were also re-dispersed at $2000 \mathrm{rpm}$ for three minutes using a high-speed disperser. For the measurements, a $25 \mathrm{~mm}$ diameter parallel plate was applied. Around $0.5 \mathrm{ml}$ of coating sample was placed on the heating plate of the rheometer, followed by lowering of the upper plate onto the sample (any excess coating forced out between the two plates was removed with a piece of tissue). The plate gap used for the rheometer was $200 \mu \mathrm{m}$, selected from a rule of thumb stating that the gap width should be 10 times larger than the maximum particle size.

During the measurement, increasing shear rates from 0.5 to $500 \mathrm{~s}^{-1}$ were imposed, using a pre-set program and an applied shear stress between 1 and $650 \mathrm{~Pa}$. The uncertainty in measured values for this method is about $2 \%$ for parallel-plate geometries, when the shear rate is larger than $1 \mathrm{~s}^{-1}$ [51].

\section{The Stormer viscometer}

For reasons of comparison, a simple KR140 Stormer viscometer (paddle geometry of stirring head), produced by Research Equipment (London) Ltd., was also used in the investigation. In this case, a constant rotation speed of $200 \mathrm{rpm}$ was applied, corresponding to an average shear rate of around $40 \mathrm{~s}^{-1}$ [52]. The associated shear stress is not well defined, but an average value between 55 and $100 \mathrm{~Pa}$ has been reported for the Stormer viscometer [53]. The instrumental uncertainty is less than 3\% [54], while, the experimental uncertainty, related to the formulation of coatings, was around 5\%, estimated from repetitions with three individual samples by viscosity measurements. The Stormer viscometer provides measurements in Krebs Units (KU) or centipoises. The measurement range is from 40 to $140 \mathrm{KU}$ or 150 to 4000 centipoises (1000 centipoise equals 1 $\mathrm{Pa} \cdot \mathrm{s})$. The Stormer viscometer is used for fast and crude measurements in coatings productions and was selected here due to its abundance. Other common types, e.g. the so-called Brookfield viscometer, could also have been chosen.

\section{Comparison between different methods}

The applicability range of the three methods and the typical viscosity range of the coatings allowed are provided in Figure 2. 


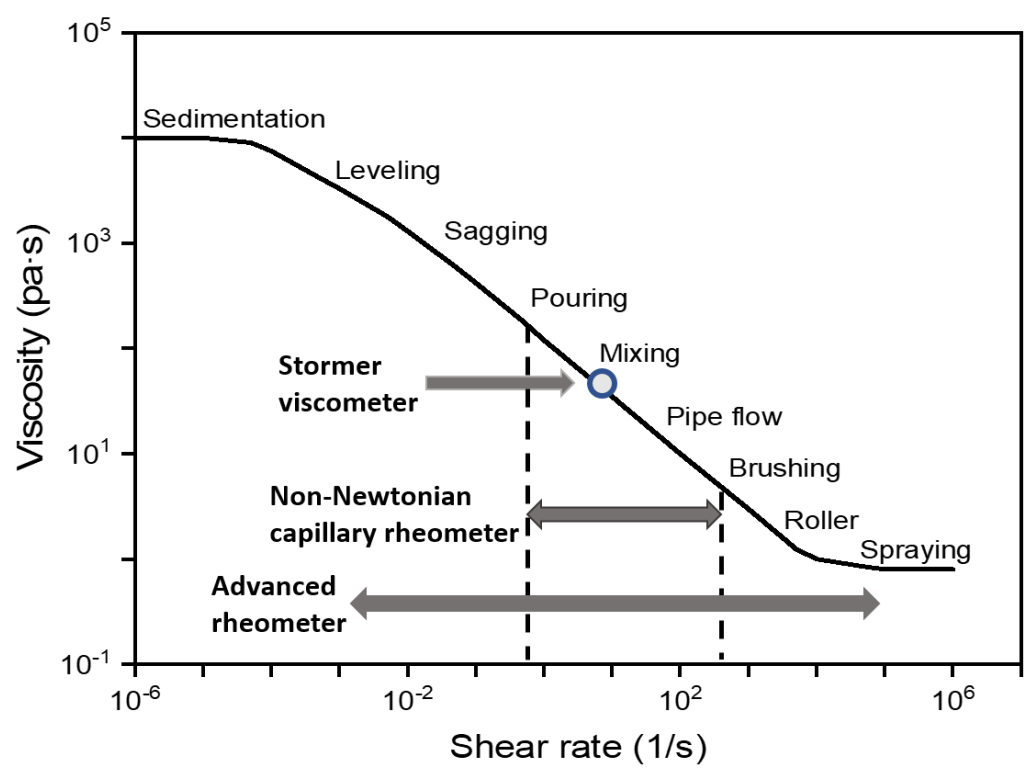

Figure 2. Qualitative overview of the shear rate analysis range for the three rheological methods. The coatings phenomena corresponding, approximately, to the various shear rates are indicated in the figure. Note, as pointed out by Eley [81] and adopted in the present work, that the shear stress (as opposed to the shear rate) is the correct independent variable to use for rheological evaluation of coating performance. However, in the case of rheological coatings phenomena, the general graphical representation becomes challenging and was not attempted.

The time required for a measurement in the non-Newtonian capillary rheometer is longer than for the Stormer viscometer, because the capillary rheometer needs to pull the sample inside the syringe and then pump it through the flow cell eight times at different flow rates to obtain the viscosity results at different shear stresses. However, when using the Stormer viscometer, time is required for the sample to cool after heating up (e.g. during a dispersion step), whereas the capillary rheometer and advanced rheometers, due to the presence of an internal heat exchanger, can cool the sample rapidly. In addition, taking into account the manual sampling time and the actual measurement time during production, which could take 15-30 minutes for both the advanced rheometer and the Stormer viscometer [10], the on-line measurement is faster; everything takes place in about 10 minutes (only 2-3 minutes for non-thixotropic samples where pre-shearing can be left out). 
For all coating samples, the measurement range of the non-Newtonian capillary rheometer is more limited compared to the advanced rheometer. This limitation is due to the flow rate of the fluid in the instrument. High flow rates could generate high pressure drops that exceed the capacity of the syringe pump, while low flow rates result in a significant increase in the time required for the measurement.

\section{Results and Discussion}

In this section, the results of measurements with the three rheometers are compared.

\section{Evaluation of Reynolds numbers for the non-Newtonian capillary rheometer}

An assumption underlying the non-Newtonian capillary rheometer calculations is that the fluid flow must be laminar. To ensure this in our analysis, the Reynolds number (Re) for cylindrical pipe flow is calculated from [55]

$$
R e=\frac{D \rho u}{\eta}
$$

where $\mathrm{D}$ is the diameter of the capillary tube, $\rho$ is the density of the fluid, $u$ is the velocity of the fluid, and $\eta$ is the viscosity of the fluid.

In Figure 3, the Reynolds number as a function of pumping speed for different relevant viscosities and using a typical coating density of $1100 \mathrm{~kg} / \mathrm{m}^{3}$ is shown.

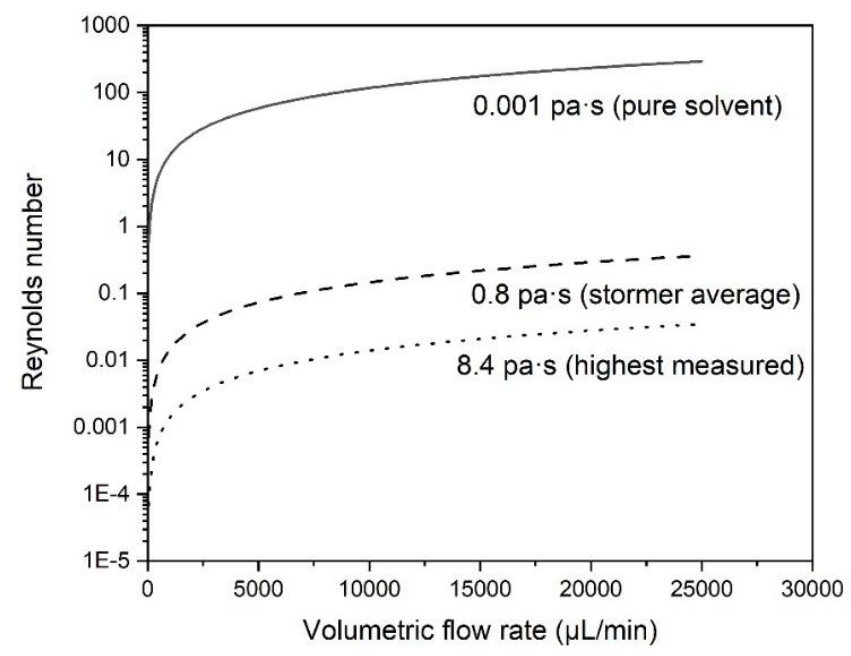

Figure 3. The Reynolds number as a function of pumping speed when assuming a fluid density of $1100 \mathrm{~kg} / \mathrm{m}^{3}$. The maximum pumping speed is $25000 \mu \mathrm{L} / \mathrm{min}$. The viscosities used in the 
calculations are for the pure solvent, the average coating viscosity of all samples measured by the Stormer viscometer, and the highest viscosity value observed (the AC-RM4 sample at a shear stress $10 \mathrm{~Pa})$.

For fully developed flow in a capillary tube, laminar flow occurs when the Reynolds number is below 2300, and turbulent flow is fully established when the Reynolds number is larger than 2900 $[56,50]$. It can be seen in Fig. 3 that even for the maximum flow rate of $25000 \mu \mathrm{L} / \mathrm{min}$, the Reynolds number of the pure solvent (which attain the highest values) confirms conditions of laminar flow.

\section{Comparison between measurements in the non-Newtonian capillary and the advanced rheometer}

For validation of the non-Newtonian capillary rheometer, experimental data should be compared to measurements obtained with the advanced rheometer.

In Figure 4, the rheological behavior of a series of acrylic-based coatings, containing different PVC levels of phthalocyanine green pigment, have been compared. The imposed shear stress was taken as the independent variable (as suggested by Eley [81]), and the viscosity and the shear rate treated as the dependent variables. 

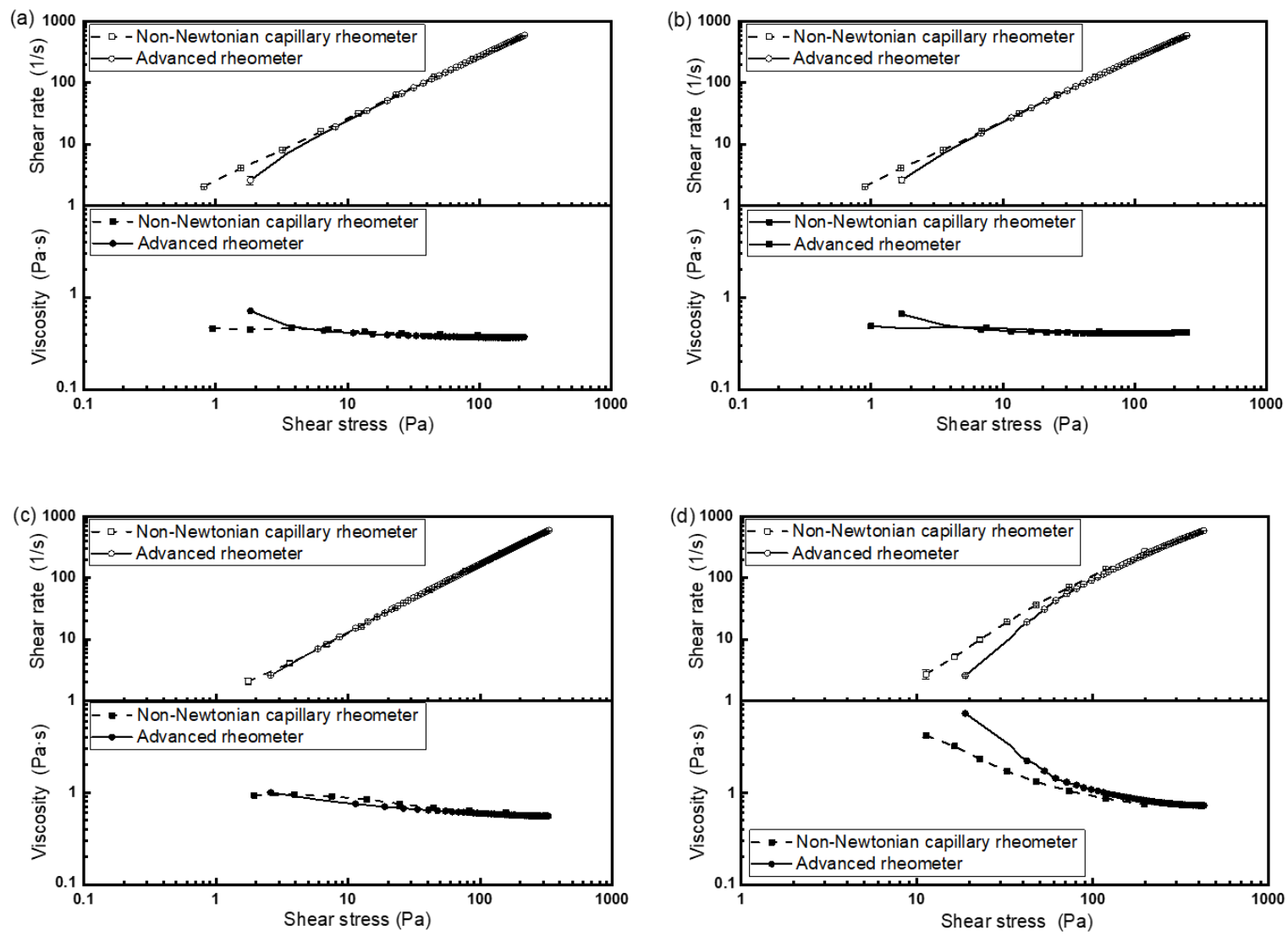

Figure 4. Comparison of viscosities and shear rates measured by the capillary (full line) and the advanced (dashed line) rheometer as a function of the imposed shear stress. The coating samples are distributed in the plots as follows: a) AC-OP1, b) AC-OP2, c) AC-OP3, d) AC-OP4.

The general tendency is that the non-Newtonian capillary rheometer measures the same or a somewhat lower viscosity than the advanced rheometer. For shear stress values exceeding 10-20 $\mathrm{Pa}$ (figures $4 \mathrm{a}, 4 \mathrm{~b}$, and $4 \mathrm{c}$ ), the viscosities measured by the non-Newtonian capillary rheometer and the advanced rheometer are basically the same, and both analytical instruments, in the shear stress range considered, have an average relative error of about $1.8 \%$ only. However, the results of figure $4 \mathrm{~d}$ and those at low shear stresses in figures $4 \mathrm{a}, 4 \mathrm{~b}$, and $4 \mathrm{c}$, show some deviation. The viscosity measurements of the non-Newtonian capillary rheometer was also compared to data from the industrially-applied Stormer viscometer (used mainly for fast and crude measurements). However, the Stormer viscometer only provides the viscosity for a single shear stress value (80 Pa). Results of the comparison are shown in Table 3. 
Table 3. Viscosities measured (at a shear stress of $80 \mathrm{~Pa}$ ) by the Stormer viscometer, the nonNewtonian capillary rheometer, and the advanced rheometer. The Stormer viscometer measurement was performed at room temperature, the non-Newtonian capillary rheometer measurement at $25 \pm 0.2{ }^{\circ} \mathrm{C}$, and the advanced rheometer measurement at $25 \pm 0.1{ }^{\circ} \mathrm{C}$. To avoid introducing uncertainty in the unit conversion for the Stormer viscometer, the viscosities are all given in Krebs Units (KU) [54].

\begin{tabular}{|c|c|c|c|}
\hline & Stormer viscometer & $\begin{array}{c}\text { Non-Newtonian } \\
\text { capillary rheometer }\end{array}$ & Advanced rheometer \\
\hline & Viscosity (KU) & Viscosity (KU) & Viscosity (KU) \\
\hline AC-IP2 & $90.23 \pm 0.40$ & $67.80 \pm 0.89$ & $78.87 \pm 8.09$ \\
\hline AC-IP3 & $90.43 \pm 0.50$ & $81.10 \pm 1.36$ & $75.23 \pm 1.99$ \\
\hline AC-IP4 & $92.27 \pm 0.70$ & $79.33 \pm 0.29$ & $82.87 \pm 7.35$ \\
\hline AC-IP5 & $92.63 \pm 0.67$ & $80.90 \pm 0.34$ & $88.50 \pm 1.85$ \\
\hline AC-RM1 & $83.53 \pm 0.65$ & $73.35 \pm 0.59$ & $77.33 \pm 1.27$ \\
\hline AC-RM2 & $95.33 \pm 0.71$ & $77.80 \pm 1.70$ & $106.12 \pm 2.24$ \\
\hline AC-RM3 & $102.33 \pm 0.50$ & $98.90 \pm 0.13$ & $116.97 \pm 4.16$ \\
\hline AC-RM4 & $112.47 \pm 0.45$ & $117.01 \pm 0.38$ & $\mathrm{NA}^{1}$ \\
\hline AC-OP1 & $57.13 \pm 0.35$ & $60.60 \pm 0.14$ & $61.10 \pm 0.26$ \\
\hline AC-OP2 & $60.47 \pm 0.15$ & $62.45 \pm 0.24$ & $62.70 \pm 0.26$ \\
\hline AC-OP3 & $68.83 \pm 0.31$ & $71.43 \pm 0.58$ & $71.90 \pm 0.10$ \\
\hline AC-OP4 & $86.17 \pm 0.21$ & $85.47 \pm 0.83$ & $91.67 \pm 1.01$ \\
\hline
\end{tabular}

1: Viscosity value too high for conversion to Krebs Unites according to table in [54].

The viscosity of the coating samples obtained by the non-Newtonian capillary rheometer varies from $60.4 \mathrm{KU}(0.36 \mathrm{~Pa} \cdot \mathrm{s})$ to $119.7 \mathrm{KU}(2.83 \mathrm{~Pa} \cdot \mathrm{s})$ at a shear stress of $80 \mathrm{~Pa}$, whereas the viscosities of all measured samples obtained by the advanced rheometer is from $62.6 \mathrm{KU}(0.40 \mathrm{~Pa} \cdot \mathrm{s})$ to 119.9 $\mathrm{KU}(2.85 \mathrm{~Pa} \cdot \mathrm{s})$ (disregarding the AC-RM4 sample). To our knowledge, an industrially-acceptable difference in the viscosity results for production purposes is less than $3 \mathrm{KU}$, when the viscosity of the sample is lower than $80 \mathrm{KU}$, and less than $5 \mathrm{KU}$ when the viscosity exceeds $80 \mathrm{KU}$. For a visual comparison of the measurements, the following ratio $\alpha$ was defined 


$$
\alpha=\frac{\eta}{\eta(\text { Stormer })}
$$

where $\eta$ is the viscosity result measured by the non-Newtonian capillary or the advanced rheometer and $\eta$ (Stormer) is the viscosity measured by the Stormer viscometer, all at $80 \mathrm{~Pa}$.

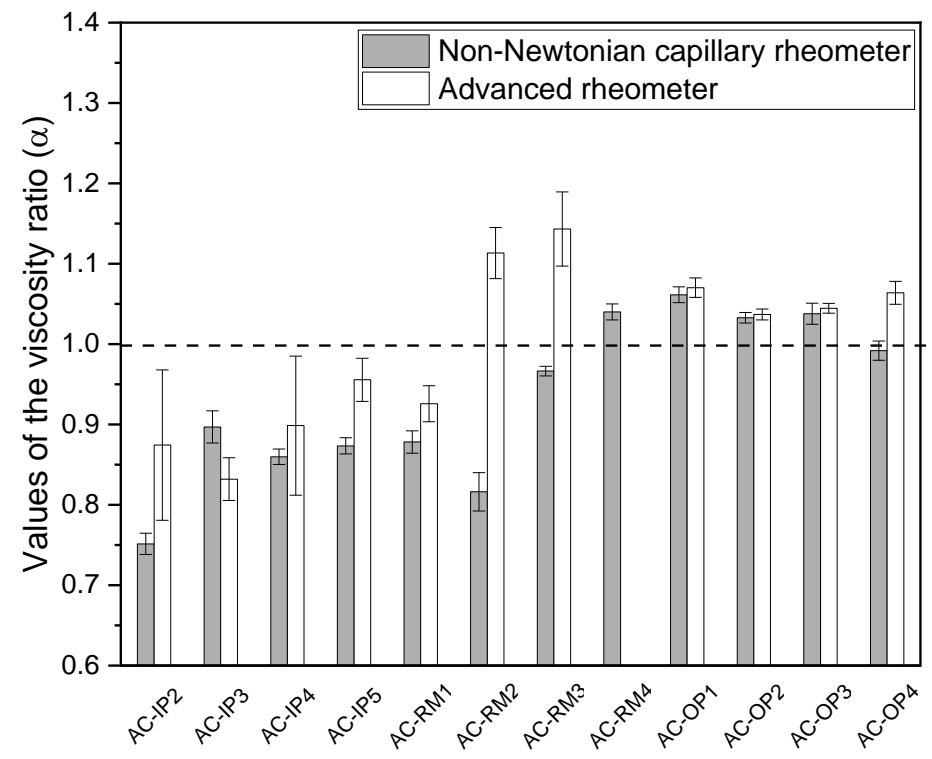

Figure 5. Values of the viscosity ratio as defined in eq (7) for the coatings investigated. The grey columns represent the non-Newtonian capillary to Stormer viscosity ratios and the white columns are the advanced to Stormer ratios. The dashed line indicates where the viscosities measured by the non-Newtonian capillary rheometer or the advanced rheometer are in agreement with those of the Stormer viscometer. The viscosity value for AC-RM4, when measured by the advanced rheometer, was too high for comparison with the Stormer data in Krebs Units (see [54]).

For most samples, there is a difference between the viscosity results obtained by the Stormer viscometer and the non-Newtonian capillary rheometer, but the deviation is not systematic; the viscosity results of AC-IP2 to AC-RM2 obtained with the non-Newtonian capillary rheometer are lower than the results obtained with the Stormer viscometer, whereas the viscosity results of the AC-RM3 to AC-OP4 samples obtained by the non-Newtonian capillary rheometer are higher than the results of the Stormer viscometer. This uncertainty may be attributed to the not very accurate average shear stress reported for the Stormer paddle viscometer (i.e. the local shear stresses may deviate significantly from the average). In fact, the Stormer viscometer is not an absolute 
viscometer, i.e. the flow field is complex and mathematically undefinable, probably anything but laminar and a quantitative comparison has to be conducted with care. The table used to convert $\mathrm{KU}$ to $\mathrm{Pa} \cdot \mathrm{s}$ (and vice versa) is provided in [54].

Despite the results of the Stormer viscometer, the general tendency is that the non-Newtonian capillary rheometer measures a lower viscosity compared with the advanced rheometer. This is seen in both Figure 4 and 5, and the difference is more significant when the when the applied shear stress is below $20 \mathrm{~Pa}$. An explanation for the difference in results is likely to be the shear history of the coating samples; although all samples, prior to measurement, were dispersed for three minutes, a difference in hold up time between the dispersing procedure and the actual measurement is evident. In the advanced rheometer, all samples were measured 3-5 minutes after the dispersion, whereas in the non-Newtonian capillary rheometer, additional shear stresses were introduced during the syringe injection process and the time from injection to actual measurement was less than one minute. Consequently, the shear history and hold up time of the two devices deviate and may well result in somewhat different viscosity values for the same coating sample.

To avoid the impact of shear history and hold up time, the viscosity of a Newtonian fluid (glycerin) was measured using both the advanced rheometer and the capillary rheometer. Within a shear stress range from 2 to $15 \mathrm{~Pa}$, the average viscosity measured by the advanced rheometer was 0.778 $\pm 0.011 \mathrm{~Pa} \cdot \mathrm{s}$, and that of the capillary rheometer was $0.784 \pm 0.014 \mathrm{~Pa} \cdot \mathrm{s}$. In general, the difference was less than about $4 \%$.

\section{Three-interval-thixotropy test}

The so-called three-interval-thixotropy-test (3ITT) [34] was conducted on the coating samples to investigate the rheological recovery time and the presence of any thixotropic effects.

The 3ITT is a step test, performed with a rotational rheometer (i.e., the advanced rheometer in this work). Generally, it consists of two different deformation types, imposed by a change in shear rate or shear stress [57]. Here, the shear rate deformation was chosen and in Figure 6 the viscosity-time recovery curves are shown. 

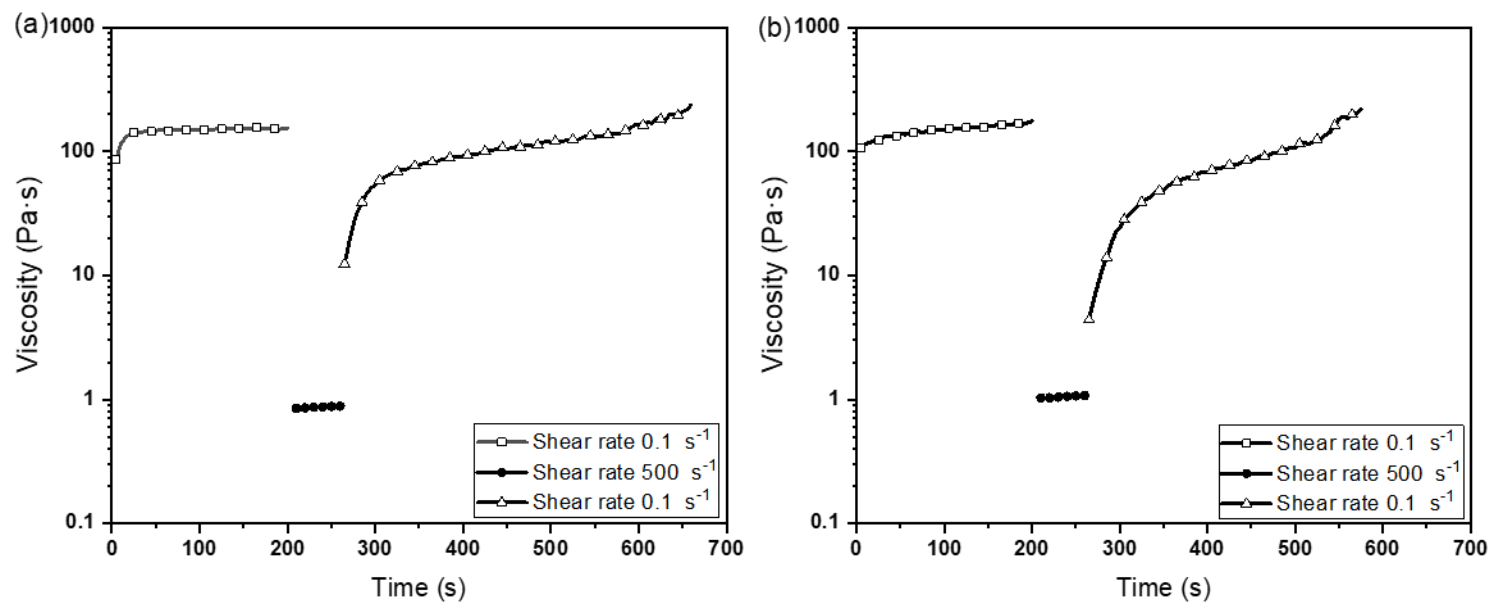

Figure 6. Three-interval-thixotropy test (3ITT) of two selected coating samples (Peak Hold). The peak hold was a process where the rotational rheometer applied a constant shear rate (either 0.1 or $500 \mathrm{~s}^{-1}$ ) to the measured sample within a certain time. a) AC-IP2 sample, b) AC-OP4 sample. The temperature was $25^{\circ} \mathrm{C}$.

As indicated in the plots, the initial stage is a low $\left(0.1 \mathrm{~s}^{-1}\right)$ shear rate period of $200 \mathrm{~s}$ followed by a high $\left(500 \mathrm{~s}^{-1}\right)$ shear rate interval lasting only $60 \mathrm{~s}$. The final stage is the recovery period, during which the low shear rate is reapplied for $600 \mathrm{~s}$.

It can be seen in Fig. 6 that when the high shear rate stage of the experiment is initiated, the viscosity of the coating sample instantly drops. During the subsequent recovery period, the viscosity of the coating gradually increases and most often returns to the initial value. Table 4 presents the average viscosity of different coating samples at the shear rates of 0.1 and $500 \mathrm{~s}^{-1}$, as well as the recovery time of each sample. As mentioned in earlier stage, the shear history and hold up time of the advanced rheometer and the capillary rheometer has a 3-5 minutes difference. According to the analyzed 3ITT results, most investigated samples have a recovery time around 5 minutes, which means this 3-5 minutes difference in hold up time could result in different viscosity results measured by the two devises.

Table 4. The average viscosity (at two values of shear rate) and the recovery time (i.e. the time required for the sample to reach $90 \%$ of the initial viscosity at a shear rate of $0.1 \mathrm{~s}^{-1}$ ) of selected 
coating samples. $\mathrm{RM}=\mathrm{Rheology}$ modifier, $\mathrm{AC}=$ acrylic based coatings, $\mathrm{IP}=$ inorganic pigment content, $\mathrm{OP}=$ organic pigment content

\begin{tabular}{|c|c|c|c|}
\hline Sample & $\begin{array}{c}\text { Viscosity at } 0.1 \mathrm{~s}^{-1} \\
(\mathbf{P a} \cdot \mathbf{s})\end{array}$ & $\begin{array}{c}\text { Viscosity at } 500 \mathrm{~s}^{-1} \\
(\mathrm{~Pa} \cdot \mathrm{s})\end{array}$ & Recovery time (s) \\
\hline AC-IP2 & $105.54 \pm 19.34$ & $1.04 \pm 0.01$ & $315 \pm 21$ \\
\hline AC-IP5 & $73.02 \pm 7.40$ & $0.83 \pm 0.02$ & $160 \pm 14$ \\
\hline AC-IP6 & $148.90 \pm 12.28$ & $1.04 \pm 0.02$ & $240 \pm 56$ \\
\hline AC-RM1 & $13.27 \pm 2.13$ & $0.91 \pm 0.02$ & $222 \pm 24$ \\
\hline AC-RM4 & $235.52 \pm 17.07$ & $1.37 \pm 0.01$ & $140 \pm 7$ \\
\hline AC-OP1 & $7.70 \pm 2.70$ & $0.52 \pm 0.02$ & $255 \pm 45$ \\
\hline
\end{tabular}

Viscosity results when taking into account thixotropic effects of coatings samples

In an attempt to reduce any differences in the measured viscosity values originating from thixotropic effects of the coatings, the software code of the non-Newtonian capillary rheometer was modified. A five minutes holding time, equivalent to that of the advanced rheometer, was inserted to take place after the coating is taken up by the syringe.
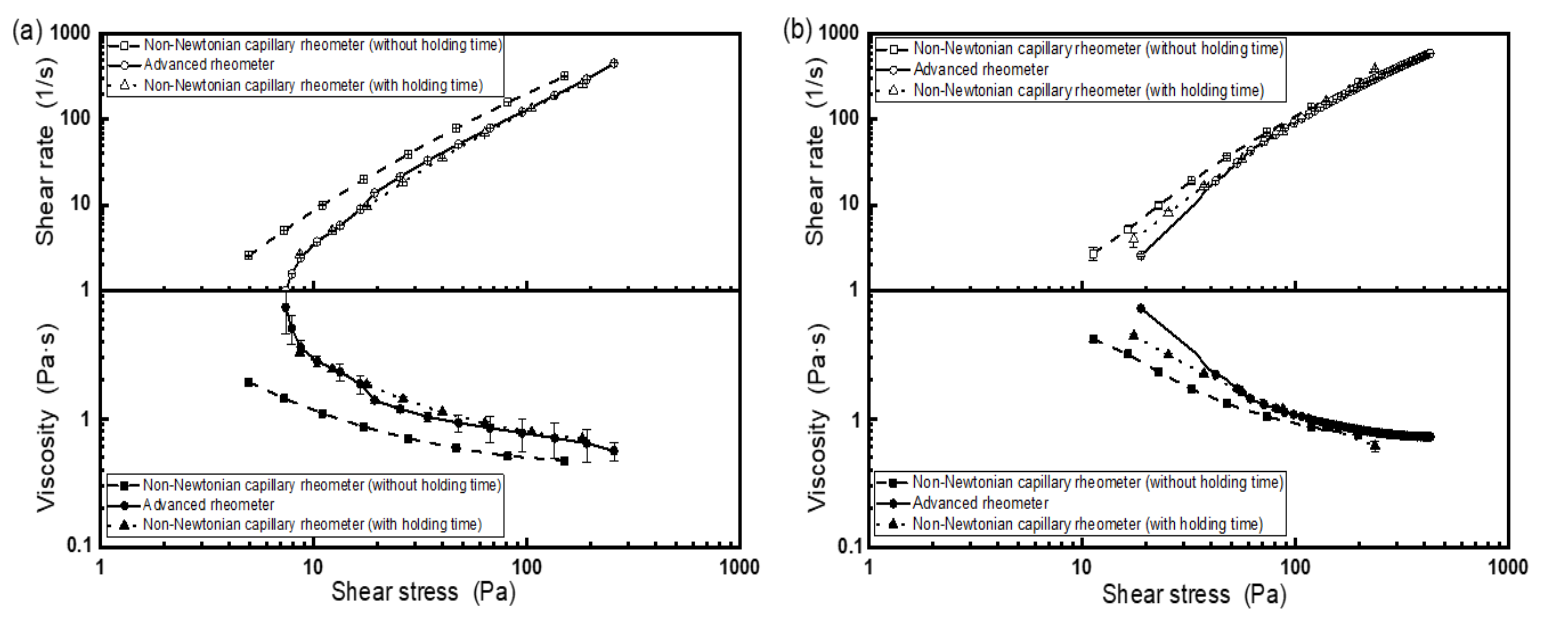

Figure 7. Comparison of viscosities and shear rates as a function of shear stress, measured by the non-Newtonian capillary rheometer (before and after adding a 5 minutes holding time) and the advanced rheometer. a) Coating sample AC-IP2 b) Coating sample AC-OP4. 
Figure 7 shows the viscosity and shear rate of AC-IP2 and AC-OP4 samples measured before and after adding a five minutes holding time in the non-Newtonian capillary rheometer analysis. The viscosity measured by the advanced rheometer is also provided. It is evident that the difference between the viscosity results of the two rheometers is effectively reduced when the five minutes holding time is included, in good agreement with the clear thixotropic behavior evidenced earlier in the 3ITT experiments. Additional results with the new procedure are shown in Table 5.

Table 5. Coating viscosities measured with the non-Newtonian capillary rheometer including a five minutes holding time (at a shear stress of $80 \mathrm{~Pa}$ ). The difference ratio $(\beta)$ column is the calculated ratio value between the results of the non-Newtonian capillary rheometer with and without a holding time and the advanced rheometer. The analysis temperature was $25 \pm 0.2{ }^{\circ} \mathrm{C}$.

\begin{tabular}{cccc}
\hline & $\begin{array}{c}\text { Capillary rheometer with } \\
\text { holding time } \\
\text { Viscosity }(\mathbf{K U})\end{array}$ & $\begin{array}{c}\text { Difference ratio }(\boldsymbol{\beta}), \\
\text { without holding time }\end{array}$ & $\begin{array}{c}\text { Difference ratio }(\boldsymbol{\beta}), \\
\text { with holding time }\end{array}$ \\
\hline AC-IP2 & $81.53 \pm 0.90$ & $0.86 \pm 0.11$ & $1.03 \pm 0.12$ \\
AC-IP3 & $84.45 \pm 0.13$ & $1.07 \pm 0.05$ & $1.12 \pm 0.03$ \\
AC-IP4 & $82.70 \pm 3.03$ & $0.95 \pm 0.08$ & $0.99 \pm 0.10$ \\
AC-IP5 & $83.57 \pm 0.38$ & $0.92 \pm 0.01$ & $0.95 \pm 0.02$ \\
AC-RM1 & $77.73 \pm 0.12$ & $0.94 \pm 0.02$ & $1.00 \pm 0.02$ \\
AC-RM2 & $\mathrm{NA}$ & $0.73 \pm 0.03$ & $\mathrm{NA}$ \\
AC-RM3 & $104.75 \pm 2.05$ & $0.84 \pm 0.03$ & $0.90 \pm 0.06$ \\
AC-RM4 & $127.05 \pm 4.88$ & $\mathrm{NA}$ & $\mathrm{NA}^{2}$ \\
AC-OP1 & $62.33 \pm 0.31$ & $0.99 \pm 0.01$ & $1.02 \pm 0.01$ \\
AC-OP2 & $63.83 \pm 0.21$ & $1.00 \pm 0.01$ & $1.01 \pm 0.01$ \\
AC-OP3 & $73.37 \pm 0.25$ & $1.00 \pm 0.01$ & $1.02 \pm 0.01$ \\
AC-OP4 & $91.63 \pm 0.40$ & $0.93 \pm 0.02$ & $1.00 \pm 0.01$ \\
\hline
\end{tabular}

1: Coating batch was consumed.

2: The ratio cannot be calculated due to the viscosity value measured by the advanced rheometer was too high for conversion to Krebs Unites according to table in [54]. 
In Table 5, it can be seen that the viscosity results after modification of the preset program of the non-Newtonian capillary rheometer are closer to the viscosity data obtained by the advanced rheometer. For most of the coating samples measured, the ratio is in the range 0.95-1.05 (i.e. less than $5 \%$ uncertainty). However, when using a shear stress below $15 \mathrm{~Pa}$, a difference between results of the two rheometers is evident, which can be seen in Figure $7 \mathrm{~b}$.

\section{Potential reasons for the lower viscosity results obtained with the Non-Newtonian capillary rheometer}

Cracg and Oene (1961) [58] claim that when capillary rheometers are used to measure the viscosity of non-Newtonian fluids, they generally produce reliable results when the applied shear stress is larger than $0.5 \mathrm{~Pa}\left(5 \mathrm{dynes} / \mathrm{cm}^{2}\right)$. At lower shear stresses, the following factors were found to affect the results [59]:

- An entrance effect at the inlet of the capillary tube

- Slip conditions at the capillary tube wall

- Surface tension effects

- Geometrical effects of the capillary tube

- Yield stress effects

- Sensor noise

Other studies have mentioned the entrance effect and explained it as being due to the time it takes for the fluid to reach a fully developed profile after entering the capillary tube from a wider tube $[60,61]$. However, all the tubes in the capillary rheometer of the present work have the same radius, so the entrance effect is not the cause of the lower viscosity measured by the capillary rheometer. The wall slip effect has been discussed in several publications [62, 63, 64]. It can sometimes be observed in tube flow experiments, where the velocity distribution of the fluid deviates significantly from the expected parabolic profile [65]. The phenomenon occurs as a critical shear stress for the interaction between the polymer structure and the tube wall [66]. Once the shear stress of the fluid exceeds the critical shear stress, the slip at the wall takes place. However, this phenomenon occurs at high flow rates only, which is not where the deviation was observed in the present work.

Another issue is the possible energy losses within the capillary tube. Malengo [67] and others [6872] have discussed the potential effects of surface tension in capillary rheometer measurements. 
Besides, Masahiro [73] discussed the effects of the surface tension at the exit of the capillary tube. Barnes [74] stated, due to the elasticity property of the fluids, that an additional pressure drop may arise at the exit of the capillary tube, which may cause a difference in the total pressure drop. However, for the specific capillary rheometer of this work, the capillary tube is filled with fluid before the actual measurement begins, that is, no gas-liquid contact will occur in the capillary tube, and the effect of surface tension is negligible. Additionally, the exit effect of the capillary tube is effectively avoided by measuring the pressure drop of the fluid before it exits.

The yield stress (i.e. the value of stress at which the material begins to flow) is another potential factor, which influences the measurements. Several studies $[68,75,76]$ have investigated the effect and ascribed it to an additional pressure drop caused by the yield stress

$$
\tau_{w}=\frac{\left(\Delta P+\Delta P_{f, y}\right) R}{2 L}
$$

where $\Delta \mathrm{P}_{\mathrm{f}, \mathrm{y}}$ is the pressure drop generated by the yield stress.

When the sample fluid is compressed into the capillary tube, an additional pressure drop is required to overcome the yield stress. However, all analyses performed in the capillary rheometer measure the pressure drop during a steady-state flow condition (the syringe pump controls the volumetric flow rate, as opposed to the pressure applied to the fluid), and the additional pressure drop caused by the yield stress will therefore not influence the measurements.

Another factor that may affect the viscosity calculation is the shape of the capillary tube. As discussed previously, the viscosity of the fluid is a function of the shear stress and the shear rate at the capillary tube wall. Both of these factors are influenced by the velocity of the fluid and the pressure drop over the capillary tube. However, there is a U-shaped bending in the current capillary rheometer, which might affect the pressure drop measurement.

The total pressure drop in a capillary tube with a bending can be calculated as the sum of two effects: the pipe wall friction, which is described by the first term on the right hand side of eq. 9 , and the additional pressure drop from the U-bending, the second term on the right hand side of equation [77]:

$$
\Delta P_{\text {bend }}=\Delta P_{f, \text { bend }}+\Delta P_{a d d}=4 f_{s}\left(\frac{l}{D}\right) \frac{\rho u^{2}}{2}+k_{b} \frac{\rho u^{2}}{2}
$$

Here, $\Delta \mathrm{P}_{\text {bend }}$ is the total pressure drop originating from the $\mathrm{U}$-bending, $\Delta \mathrm{P}_{\mathrm{f} \text {,bend }}$ is the pressure drop caused by the friction inside the bend, $\Delta \mathrm{P}_{\text {add }}$ is the additional pressure drop generated by the change of direction of the fluid inside a bend, fs is the Moody friction factor of the fluid in a straight pipe 
(for a laminar flow, $f_{s}=16 /$ Reynolds number), 1 is the length of the bend tube, which is a factor of the angle of the bend (i.e the length of the bend is calculated from the angle and the radius of the bend), $\mathrm{D}$ is the diameter of the pipe, $\rho$ is the density of the fluid, $\mathrm{u}$ is the velocity of the fluid, and $\mathrm{k}_{\mathrm{b}}$ is the bending loss coefficient.

To evaluate the effect of the pipe bending, the same values as in eq. 9 were used: $\mathrm{Q}=100 \mu \mathrm{L} / \mathrm{min}$; $\mathrm{u}=0.53 \times 10^{-3} \mathrm{~m} / \mathrm{s} ; \rho=1100 \mathrm{~kg} / \mathrm{m}^{3} ; \mathrm{D}=2 \mathrm{~mm} ; l=70 \mathrm{~mm} ; \mathrm{k}_{\mathrm{b}}=1.7 ; \mu=0.8 \mathrm{~Pa} \cdot \mathrm{s}$. Upon insertion in the right hand terms of equation (12), one gets

$$
\Delta P_{\text {bend }}=\Delta P_{f, \text { bend }}+\Delta P_{\text {add }}=247.2 \mathrm{~Pa}+2.6 \times 10^{-4} \mathrm{~Pa}=247.2 \mathrm{~Pa}
$$

The ratio between $\Delta \mathrm{P}_{\mathrm{f}, \text { bend }}$ and $\Delta \mathrm{P}_{\text {add }}$ gives

$$
\frac{\Delta P_{\text {add }}}{\Delta P_{f, \text { bend }}}=\frac{2.6 \times 10^{-4} \mathrm{~Pa}}{247.2 \mathrm{~Pa}}=1.06 \times 10^{-6}
$$

Clearly, due to the very small capillary radius and low Reynolds-number, the effect of the Ubending can be neglected.

Finally, the effect of noise in the equipment should also be considered. Especially in the case of low volumetric flow rates, the pressure drop of the fluid through the capillary is relatively low, and the accuracy of the sensor is likely to have an impact on the analysis results of the instrument. In contrast, when the fluid across the capillary tube at a high flow rate, the effect of the sensor noise only takes a very small portion of the total pressure difference. Therefore, the noise effect decreases as the volume flow rate and pressure drop increase, which means there could be a high relative error in the viscosity result under low flow rates. This phenomenon is consistent with the comparative data mentioned in the experiment.

\section{Viscosity measurements with the capillary rheometer}

The capillary rheometer should have the ability to not only monitor the viscosity change, but it must also give feedback for adjustments of the composition of the coatings product during the dispersing process in real time. As an example, the capillary rheometer was used to analyze acrylicbased coatings with different compositions to verify whether the capillary rheometer can be used to modify the dispersing process. Figure 9 displays the viscosity vs shear stress results for different coating samples measured with the capillary rheometer. 


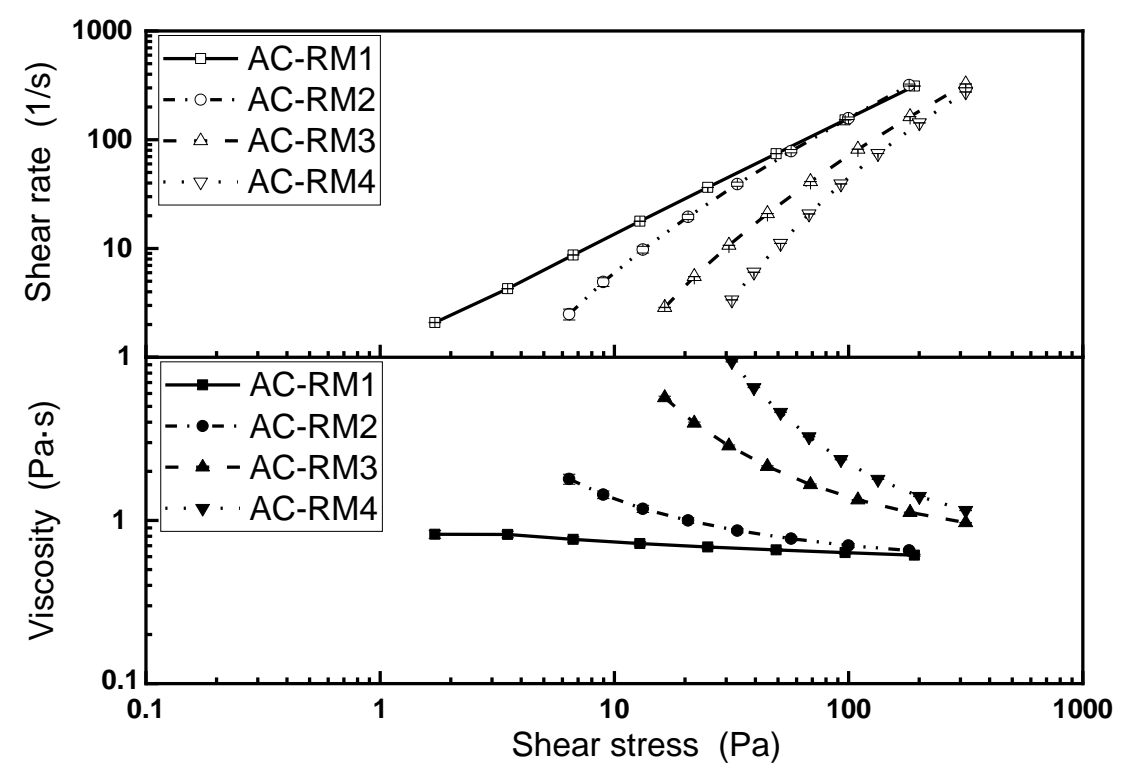

Figure 9. Viscosity as a function of stress measurements (non-Newtonian capillary rheometer) of the acrylic based coating samples containing different amounts of rheology modifier (from 0.23 wt $\%$ for AC-RM1 to $1.98 \mathrm{wt} \%$ for AC-RM4). The PVC was kept constant at $20 \%$.

The four curves from top to bottom in Figure 9 represent in turn the acrylic-based coatings with decreasing content of the rheology modifier. The viscosity of all four coatings in Figure 9 ranges from 0.5 to $10.0 \mathrm{~Pa} \cdot \mathrm{s}$ and the shear stress range of the equipment is from 1.0 to $300 \mathrm{~Pa}$. As expected, when the shear stress increases, the viscosity of the coating gradually decreases and when the content of the rheology modifier increases, the viscosity of the coating increases.

Figure 10 shows the viscosity results for coatings with different PVC of an organic pigment, green phthalocyanine. 


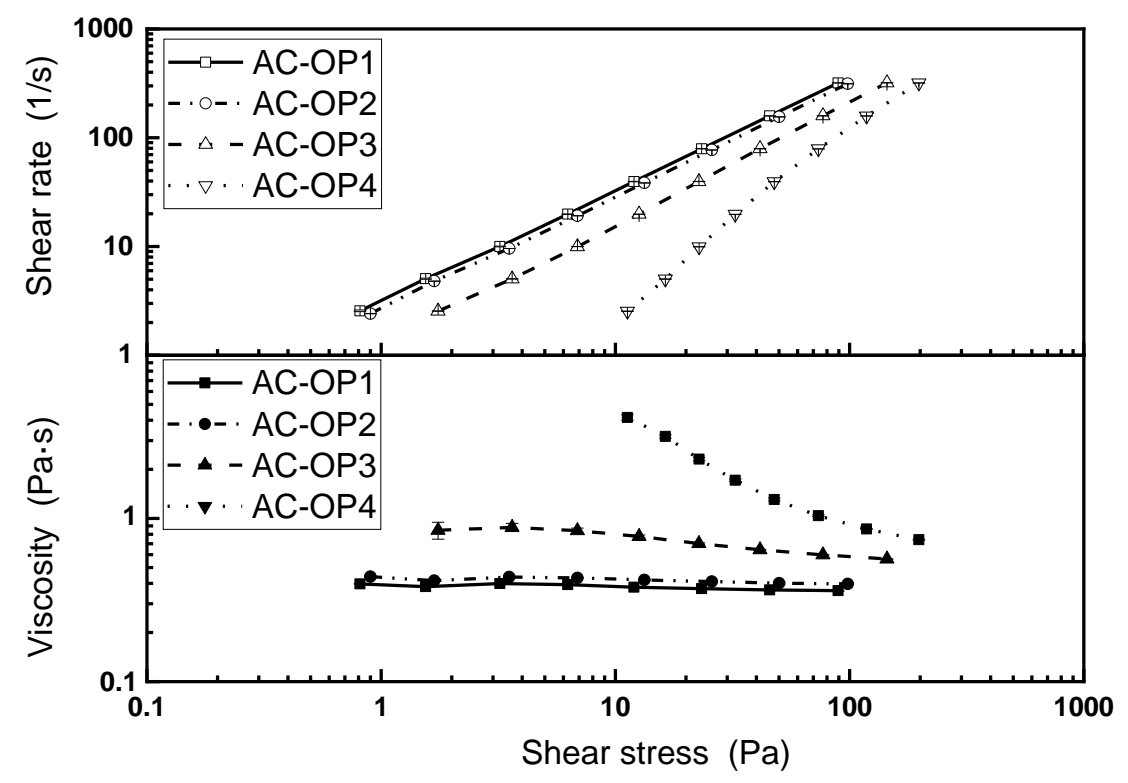

Figure 10. Viscosity as a function of stress of the acrylic based coating samples with different PVC of phthalocyanine green pigment, from $1 \%$ (AC-OP1) to $20 \%$ (AC-OP4), measured by the nonNewtonian capillary rheometer. The weight percentage of the rheology modifier was kept constant at $1.33 \mathrm{wt} \%$.

The measurements of the four samples can be clearly distinguished, and the viscosity of the ACOP1 sample barely changed within the analytical range of the capillary rheometer. A higher PVC should result in a higher viscosity, and this effect is clear in the figure.

In summary, the non-Newtonian capillary rheometer has a sufficiently high resolution for guiding the formulation work. When used in an industrial production line, the non-Newtonian capillary rheometer can be applied directly on a well-stirred mixing tank or at any installed recirculation loop from a mixing or holding tank.

\section{Conclusions}

During production, the viscosity is one of the most important quality control parameters for coatings. Currently, a single-shear stress off-line viscosity measurement is typically applied in the coatings industry. 
In this work, we investigated the use of an on-line non-Newtonian capillary rheometer for coating products. For validation, the viscosity of three series of acrylic-based coating samples were measured, at shear stresses from 1.0 to $400 \mathrm{~Pa}$ and the results compared to those obtained with an advanced off-line research rheometer.

Apart from some deviation at the low end of the shear stress spectrum, excellent agreement between the two rheometers was found when the sample holding time and pre-shearing were properly controlled.

In addition, for all values of shear stresses considered, the resolution of the non-Newtonian capillary rheometer was sufficiently high to detect the viscosity changes associated with perturbations in the PVC and the concentration of rheology modifier in the coatings.

Compared to the analytical methods commonly employed in the industry, important advantages of the non-Newtonian capillary rheometer are that the apparatus covers a wide range of shear stresses in a fully automated mode with a low measurement time. In future work, a wider range of coatings will be considered.

\section{Acknowledgement}

Financial support from The Hempel Foundation to CoaST (The Hempel Foundation Coating Science and Technology Centre) is gratefully acknowledged.

\section{References}

[1] Gérardy, R, Emmanuel, N, Toupy, T, Kassin, VE, Tshibalonza, NN, Schmitz, M, Monbaliu, JCM, "Continuous flow organic chemistry: successes and pitfalls at the interface with current societal challenges." European Journal of Organic Chemistry, 2018 (20-21) 2301-2351 (2018)

[2] Cervera-Padrell, AE, Skovby, T, Kiil, S, Gani, R, Gernaey, KV, "Active pharmaceutical ingredient (API) production involving continuous processes-a process system engineering (PSE)assisted design framework." European Journal of Pharmaceutics and Biopharmaceutics, 82 (2) 437-456 (2012)

[3] May, SA, "Flow chemistry, continuous processing, and continuous manufacturing: A pharmaceutical perspective." Journal of Flow Chemistry, 7 (3-4) 137-145 (2017)

[4] Malhotra, G, "Pharmaceutical processing_batch or a continuous process: a choice." Pharm Process, 16-17 (2009) 
[5] Partovi, FY, "An analytical model of process choice in the chemical industry." International Journal of Production Economics, 105 (1) 213-227 (2007)

[6] Hans-Joachim, S, Goldschmidt, A, BASF Handbook Basics of Coating Technology. European Coatings, Hamnover (2018)

[7] Wicks, ZW, Jones, FN, Pappas, SP, Douglas, AW, Organic coatings: science and technology $3^{\text {rd }}$ Edition. John Wiley \& Sons, Hoboken (2007)

[8] Schmollgruber F (2015) Choosing the Right Spectrophotometer. https://www.pcimag.com/articles/100526-choosing-the-right-spectrophotometer Accessed 28 May 2020

[9] Page, T, Dubina, H, Fillipi, G, Guidat, R, Patnaik, S, Poechlauer, JC, "Equipment and analytical companies meeting continuous challenges. May 20-21, 2014 Continuous Manufacturing Symposium." Journal of pharmaceutical sciences, 104 (3) 821-831 (2015)

[10] Lane, JL, Henderson, KO, "Viscosity measurement: So easy, yet so difficult." ASTM Standardization News, 32 (6) (2004)

[11] Gulrajani, ML, Colour measurement: principles, advances and industrial applications. Elsevier, New York (2010)

[12] Tracton, AA, Coatings technology handbook. CRC press, Boca Raton (2005)

[13] Lee, SL, O’Connor, TF, Yang, X, Cruz, CN, "Modernizing pharmaceutical manufacturing: from batch to continuous production." Journal of Pharmaceutical Innovation, 10 (3) 191-199 (2015) [14] Gupta, SV, Commercial Viscometers. In Viscometry for Liquids. Springer, Berlin (2014)

[15] Liptak, BG, Instrument Engineers' Handbook, Volume One: Process Measurement and Analysis. CRC press, Boca Raton (2003)

[16] Durdag K (2006) On-Line Viscosity Measurement. https://www.pcimag.com/articles/94508on-line-viscosity-measurement Accessed 28 Jan 2020

[17] New REL KR140 Viscometer https://www.khushbooscientific.com/website/Cone-PlateViscometers-Rheometers.htm Accessed 01 May 2020

[18] HAAKETM Falling Ball C https://www.thermofisher.com/order/catalog/product/3560001?SID=srch-srp3560001\#/3560001?SID=srch-srp-3560001 Accessed 01 May 2020 [19] Hammers $\quad \mathrm{S} \quad$ (2009) KROHNE $\quad$ OPTISONIC 6300. https://www.fagerberg.dk/Produkter/KrohneOptisonic-6300 Accessed 01 May 2020 
[20] Electromagnetic Viscometer (EV 1000) https://www.vinci-technologies.com/productsexplo.aspx ?IDM=601176\&IDR=82291 \&IDR2=82560 Accessed 03 May 2020

[21] University of Toronto (2010) AR2000 Rheometer http://www2.mie.utoronto.ca/labs/rheology/instrumentation.html Accessed 03 May 2020 [22] BROOKFIELD ENGINEERING LABORATORIES, INC (1998) BROOKFIELD DIGITAL RHEOMETER MODEL DV-III+ Operating Instructions Manual. http://www.laier.be/files/brookfield_operating_instructions_dv_3_ultra.pdf Accessed 24 May 2020

[23] Cho, YI, Hartnett, JP, Lee, WY, "Non-Newtonian viscosity measurements in the intermediate shear rate range with the falling-ball viscometer." Journal of non-newtonian fluid mechanics, 15 (1) 61-74 (1984)

[24] Rabani, A, Pinfield, VJ, Richard EC, "Rate of shear of an ultrasonic oscillating rod viscosity probe." Ultrasonics, 65 18-22 (2016)

[25] Zhao, H, Memon, A, Gao, J, Taylor, SD, Sieben, D, Ratulowski, J, "Heavy oil viscosity measurements: Best practices and guidelines." Energy \& Fuels, 30 (7) 5277-5290 (2016)

[26] Dao, TT, Ye, AX, Shaito, AA, Roye, N, Hedman, K, "Capillary Rheometry: Analysis of LowViscosity Fluids, and Viscous Liquids and Melts at High Shear Rates." American Laboratory, 41 14 (2009)

[27] Barel, AO, Paye, M, Maibach, HI, Handbook of cosmetic science and technology. CRC press, Boca Raton (2014)

[28] Abbas, KA, Abdulkarim, SM, Saleh, AM, Ebrahimian, M, "Suitability of viscosity measurement methods for liquid food variety and applicability in food industry-A review." Journal of Food, Agriculture, \& Environment, 8 (3) 100-107 (2010)

[29] Patton, Temple C, "Paint flow and pigment dispersion." Paint Flow and Pigment Dispersion. 479-479 (1964)

[30] Mert, B, Sumali, H, Campanella, OH "A new method to measure viscosity and intrinsic sound velocity of liquids using impedance tube principles at sonic frequencies." Review of scientific instruments, 75 (8) 2613-2619 (2004)

[31] Schirru, M, Development of an ultrasonic sensing technique to measure lubricant viscosity in engine journal bearing in-situ. Springer, Berlin (2017) 
[32] Durdag, K, "Solid state acoustic wave sensors for real-time in-line measurement of oil viscosity." Sensor Review, 28 (1) 68-73 (2008)

[33] Turpeinen, T, Jäsberg, A, Haavisto, S, Liukkonen, J, Salmela, J, Koponen, AI, "Pipe rheology of microfibrillated cellulose suspensions." Cellulose, 27 (1) 141-156 (2020)

[34] Mezger, T, The rheology handbook, $3^{\text {rd }}$ edition. Vincentz Network, Hannover (2011)

[35] Kalotay, P, "On-line viscosity measurement using Coriolis mass flowmeters." Flow Measurement and Instrumentation, 5 (4) 303-308 (1994)

[36] Kim, BJ, Lee, SY, Jee, S, Atajanov, A, Yang, S, "Micro-viscometer for measuring shearvarying blood viscosity over a wide-ranging shear rate." Sensors, 17 (6) 1442 (2017)

[37] Mason, WP, Baker, WO, McSkimin, HJ, Heiss, JH, "Measurement of shear elasticity and viscosity of liquids at ultrasonic frequencies." Physical Review, 75 (6) 936 (1949)

[38] Hertz, TG, Dymling, SO, Lindström, K, Persson, HW, "Viscosity measurement of an enclosed liquid using ultrasound." Review of scientific instruments, 62 (2) 457-462 (1991)

[39] Shiokawa, S, Kondoh, J, "Surface Acoustic Wave Sensors." Japanese Journal of Applied Physics, 43 2799-2802 (2004)

[40] Joshi, SG, "Flow Sensor using Surface Acoustic Waves." Ultrasonics Symposium, 555-558 (1988)

[41] Wiklund, J, Shahram, I, Stading, M, "Methodology for in-line rheology by ultrasound Doppler velocity profiling- and pressure difference techniques." Chemical Engineering Science, 62 42774293 (2007)

[42] Jørgensen, SB, "Quality Control for Efficient In-line Coating Production." Technical University of Denmark, Master's thesis (2018)

[43] Digilov, RM, "Pressure-driven capillary viscometer: Fundamental challenges in transient flow viscometry." Review of Scientific Instruments, 82 (12), 125111 (2011)

[44] Jones, FN, Nichols, ME, Pappas, SP Organic coatings: science and technology. John Wiley \& Sons, Hoboken (2017)

[45] Kim, S, Cho, YI, Kensey, KR, Pellizzari, RO, Stark, PR, "A scanning dual-capillary-tube viscometer." Review of Scientific Instruments, 71 (8) 3188-3192 (2000)

[46] Lambourne, R, Strivens, TA, Paint and surface coatings: theory and practice. Elsevier, New York (1999) 
[47] Mooney, M, "Explicit formulas for slip and fluidity." Journal of Rheology (1929-1932), 2 (2) 210-222 (1931)

[48] Zhang, X, Fundamentals of fiber science. DEStech Publications, Lancaster (2014).

[49] Schramm, G, A practical approach to rheology and rheometry. Gebrueder HAAKE GmbH, Karlsruhe (1994).

[50] McCabe, WL, Julian, CS, Peter, H, Unit operations of chemical engineering ( $7^{\text {th }}$ edition). McGraw-hill, New York (2004)

[51] Escudier, MP, Gouldson, IW, Pereira, AS, Pinho, FT, Poole, RJ, "On the reproducibility of the rheology of shear-thinning liquids." Journal of Non-Newtonian Fluid Mechanics, 97 (2-3) 99124 (2001)

[52] Rheology and Viscosity Measurements: Their Relation to the Properties of Water-based Coatings." Pigment \& Resin Technology, 23 (3) 11-13 (1994)

[53] Eley, RR, "Applied rheology in the protective and decorative coatings industry." Rheology Reviews 2005, 173 (2005)

[54] Brookfield KU-2 Viscometer Operating Instructions. Brookfield Engineering Laboratories, INC, Middleboro (2004)

[55] Bird, RB, Stewart, WE, Lightfoot, EN, Transport Phenomena. John Wiley \& Sons, Hoboken (2006)

[56] Gersten, K, Boundary-layer theory. Springer, Berlin (2017)

[57] Yilmaz, MT, Vatansever, C, "Three interval thixotropy test to determine structural regeneration of a glucomannan based hydrocolloid film at air/water interface: Interfacial, molecular, thermal and surface characterization." Food hydrocolloids, 61 458-468 (2016)

[58] Cragg, LH, Oene, HV, "Shear dependence in the viscometry of high polymer solutions: A new variable-shear capillary viscometer." Canadian Journal of Chemistry, 39 (1) 203-215 (1961) [59] Marvin, RS, "The accuracy of measurements of viscosity of liquids." J Res Natl Bur Stand Sect A, 75 (6) 535-540 (1971)

[60] Southern, JH, Roger, SP, "The properties of polyethylene crystallized under the orientation and pressure effects of a pressure capillary viscometer." Journal of Applied polymer science, 14 (9) 2305-2317 (1970)

[61] Kamal, MR, Hla, N, "Capillary viscometry: a complete analysis including pressure and viscous heating effects." Polymer Engineering \& Science, 20 (2) 109-119 (1980) 
[62] Churaev, NV, Sobolev, V. D., Somov, A. N., "Slippage of liquids over lyophobic solid surfaces." Journal of Colloid and Interface Science, 97 (2) 574-581 (1984)

[63] Pit, R, Hervet, H, Leger, L, "Direct experimental evidence of slip in hexadecane: solid interfaces." Physical review letters, 85 (5) 980 (2000)

[64] Craig, VSJ, Chiara, N, David, RMW, "Shear-dependent boundary slip in an aqueous Newtonian liquid." Physical review letters, 87 (5) 054504 (2001)

[65] Luk, S, Raj M, Diran, A, "Experimental observations of wall slip: tube and packed bed flow." Industrial \& engineering chemistry research, 26 (8) 1609-1616 (1987)

[66] Granick, S, Yingxi, Z, Hyunjung, L, "Slippery questions about complex fluids flowing past solids." Nature materials, 2 (4) 221 (2003)

[67] Malengo, A, "Surface tension effects in capillary viscometers: an evaluation with an experimental comparative analysis." Metrologia, 46 (5) 496 (2009)

[68] Kim, S, Cho, YI, Hogenauer, WN, Kensey, KR, "A method of isolating surface tension and yield stress effects in a U-shaped scanning capillary-tube viscometer using a Casson model." Journal of non-newtonian fluid mechanics, 103 (2-3) 205-219 (2002)

[69] Einfeldt, J, "Comments on high-accuracy viscosity measurements using capillary viscometers." Metrologia, 38 (5) 459 (2001)

[70] Uitterdijk, SJ, "Method for reducing surface-tension effects in relative viscosity measurements with Ostwald-type viscometers." Metrologia, 34 (2) 153 (1997)

[71] Wedlake, GD, Vera, JH, Ratcliff, GA, "Identification of a previously undetected source of systematic error in capillary viscometry measurements." Review of Scientific Instruments, 50 (1) 93-98 (1979)

[72] Einfeldt, J, N, Schmelzer, "Theory of capillary viscometers taking into account surface tension effects." Rheologica Acta, 21 (1) 95-102 (1982)

[73] Karasawa, M, Hasegawa, T, Narumi, T, "Measurement of dynamic surface tension of surfactant solutions." Nihon Reoroji Gakkaishi, 35 (5) 265-271 (2007)

[74] Barnes, HA, Hutton, JF, Walters, K, An introduction to rheology (Vol. 3). Elsevier, New York (1989)

[75] Bird, RB, Armstrong, RC, Hassager, O, Dynamics of polymeric liquids. Vol. 1: Fluid mechanics. John Wiley and Sons Inc, New York (1987) 
[76] Walawender, WP, Te, YC, David, FC, "An approximate Casson fluid model for tube flow of blood." Biorheology, 12 (2) 111-119 (1975)

[77] Clement, K, Fangel, P, Jensen, AD, Thomsen, K, Kemiske enhedsoperationer. (In Danish). Polyteknisk Forlag, Kongens Lyngby (2004)

[78] Tracton, AA, Coatings technology handbook. CRC press, Boca Raton, (2005)

[79] Ji, H, Lim, HM, Chang, YW, "Comparison of the Viscosity of Ceramic Slurries using a Rotational Rheometer and a Vibrational Viscometer." Journal of the Korean Ceramic Society, 49

(6) 542 (2012)

[80] Nwosu, OU, Ewulonu, CM, "Rheological behaviour of eco-friendly drilling fluids from biopolymers." Journal of Polymer and Biopolymer Physics Chemistry, 2 (3) 50-54 (2014) [81] Eley, RR, "Applied rheology and architectural coating performance." Journal of Coatings Technology and Research, 16 (2) 263-305 (2019)

[82] ASTM D281-95(2007), Standard Test Method for Oil Absorption of Pigments by Spatula Rub-out, ASTM International, West Conshohocken, PA, (2007) doi:10.1520/D0281-95R07. 